\title{
The Basophil Activation Test: A Sensitive Test in the Diagnosis of Allergic Immediate Hypersensitivity to Pristinamycin
}

\author{
Sébastien Viel ${ }^{\mathrm{a}, \mathrm{e}}, \mathrm{f} \quad$ Lorna Garnier $^{\mathrm{a}} \quad$ Elodie Joly $^{\mathrm{b}}$ Paul Rouzaire $^{\mathrm{g}}$ Audrey Nosbaum $^{\mathrm{b}, \mathrm{e}, \mathrm{f}}$, \\ Pauline Pralong $^{b}$ Amélie Faude $^{c}$ Catherine Rioufol $^{c-e}$ Françoise Bienvenu $^{a}$ \\ Jacques Bienvenu ${ }^{a, e, f}$ Frédéric Berard ${ }^{b, e, f}$ \\ a Laboratoire d'Immunologie, 'b Service d'Immunologie Clinique et d'Allergologie, and 'Département de Pharmacie \\ Clinique et Médicaments, Centre Hospitalier Lyon Sud, Hospices Civils de Lyon, and d Ciblage Thérapeutique et \\ Oncologique, EMR3738, Pierre-Bénite, e Université Claude Bernard Lyon 1, Villeurbanne, ${ }^{\mathrm{f}}$ Centre International de \\ Recherche en Infectiologie, CIRI, Inserm U1111, CNRS UMR5308, ENS de Lyon, UCBL1, Lyon, and \\ gService d'Immunologie, CHU de Clermont-Ferrand, Clermont-Ferrand, France
}

\section{Key Words}

Basophil activation test $\cdot$ CD203C $\cdot$ Immediate-type hypersensitivity Skin tests

\begin{abstract}
Immediate hypersensitivity (IHS) reactions to macrolides and to macrolide-derived antibiotics like pristinamycin are uncommon. In this context, there is little data available to appreciate the true value of biological tools regarding the diagnosis of immediate allergy to pristinamycin. Here we assess the clinical usefulness of the basophil activation test (BAT) to differentiate allergic from nonallergic IHS to pristinamycin. Thirty-six patients were tested with skin tests as the gold standard and BAT. The BAT achieved a sensitivity of $76 \%$ and a specificity of $100 \%$, implying an absence of false positive results. Multicenter studies remain to be performed to better define the sensitivity, specificity and interlaboratory variation of BAT in the diagnosis of allergy to pristinamycin and macrolides.

C 2015 S. Karger AG, Basel
\end{abstract}

J. Bienvenu and F. Berard contributed equally to this work.

\section{Introduction}

Adequate medical management of immediate hypersensitivity (IHS) to drugs requires the distinction between allergic IHS (AIHS) and nonallergic reactions. Routinely, in addition to the patient's medical history, skin tests and, if appropriate, provocation tests are used for diagnosis. However, skin tests have the potential to induce anaphylaxis episodes [1]. Even though biological assays, as specific IgE detection, may be performed, they generally have a low sensitivity [2]. Moreover, such tests are commercially available for a limited number of drugs that do not include pristinamycin. In this regard, it is of interest to develop safe and highly specific in vitro tools for diagnosis of AIHS to pristinamycin and, to a larger extent, to macrolides.

Pristinamycin is an antibiotic related to the macrolide family, extracted from Streptomyces pristinaespiralis. It is composed of two molecules: pristinamycin IA, a depsipeptide, and pristinamycin IIA, a macrolide. This antibiotic is primarily used in the context of bronchopulmonary, genital and cutaneous infections, mostly for its antimicrobial activities against Gram-positive cocci. Hypersensitivity reactions to pristinamycin are rare and

Correspondence to: Dr. Sébastien Viel

Laboratoire d'Immunologie, Centre de Biologie Sud, Centre Hospitalier Lyon Sud 165 Chemin du Grand Revoyet

FR-69495 Pierre-Bénite (France)

E-Mail sebastien.viel@chu-lyon.fr 
Table 1. Demographical, clinical and biological characteristics of the 21 patients with a confirmed AIHS to pristinamycin

\begin{tabular}{|c|c|c|c|c|c|c|c|c|c|c|c|c|c|}
\hline \multirow[t]{2}{*}{ Sex } & \multirow[t]{2}{*}{$\begin{array}{l}\text { Age, } \\
\text { years }\end{array}$} & \multirow{2}{*}{$\begin{array}{l}\text { Time of } \\
\text { symptom } \\
\text { onset }\end{array}$} & \multirow[t]{2}{*}{$\begin{array}{l}\text { Severity } \\
\text { grading }\end{array}$} & \multicolumn{3}{|c|}{ Clinical symptoms } & \multirow[t]{2}{*}{$\begin{array}{l}\text { Prick } \\
\text { test }\end{array}$} & \multirow[t]{2}{*}{$\begin{array}{l}\text { IDT } \\
\text { (dilution) }\end{array}$} & \multirow[t]{2}{*}{$\begin{array}{l}\text { Oral } \\
\text { challenge }\end{array}$} & \multirow[t]{2}{*}{ BAT result } & \multicolumn{3}{|c|}{$\begin{array}{l}\% \text { CD } 203 \text { c for } 3 \text { pristinamycin } \\
\text { concentrations }\end{array}$} \\
\hline & & & & cutaneous & digestive & respiratory & & & & & $1 \mathrm{mg} / \mathrm{ml}$ & $0.5 \mathrm{mg} / \mathrm{ml}$ & $0.1 \mathrm{mg} / \mathrm{ml}$ \\
\hline $\mathrm{F}$ & 52 & $<1 \mathrm{~h}$ & II & + & - & + & + & ND & ND & Negative & & & \\
\hline $\mathrm{F}$ & 41 & $<1 \mathrm{~h}$ & III & + & + & + & + & ND & ND & Positive & 79 & 79 & 81 \\
\hline $\mathrm{F}$ & 72 & $<1 \mathrm{~h}$ & III & + & - & + & + & ND & ND & Positive & 25 & 25 & 22 \\
\hline $\mathrm{F}$ & 45 & $4 \mathrm{~h}$ & II & + & - & - & - & $+(1 / 100)$ & ND & Positive & 10 & 4 & 1 \\
\hline $\mathrm{F}$ & 30 & $<1 \mathrm{~h}$ & II & + & - & + & + & ND & ND & Positive & 76 & 76 & 60 \\
\hline $\mathrm{F}$ & 62 & $4 \mathrm{~h}$ & III & + & - & + & + & ND & ND & Positive & 58 & 45 & 48 \\
\hline $\mathrm{F}$ & 43 & $<1 \mathrm{~h}$ & I & + & - & - & - & $+(1 / 100)$ & ND & Positive & 4.5 & 10 & 10 \\
\hline $\mathrm{F}$ & 39 & $<1 \mathrm{~h}$ & I & + & - & - & - & $+(1 / 100)$ & ND & Negative & & & \\
\hline $\mathrm{F}$ & 42 & $<1 \mathrm{~h}$ & I & + & - & - & - & $+(1 / 1,000)$ & ND & Positive & 92 & 93 & 92 \\
\hline M & 54 & $<1 \mathrm{~h}$ & II & + & + & + & + & ND & ND & Positive & NA & NA & NA \\
\hline M & 60 & $<1 \mathrm{~h}$ & II & + & + & + & + & $+(1 / 1,000)$ & ND & Positive & NA & NA & NA \\
\hline $\mathrm{F}$ & 58 & $<1 \mathrm{~h}$ & II & + & - & + & + & ND & ND & Positive & NA & NA & NA \\
\hline M & 21 & $<1 \mathrm{~h}$ & II & + & - & + & - & $+(1 / 100)$ & ND & Positive & NA & NA & NA \\
\hline
\end{tabular}

IDT = Intradermal test $\mathrm{ND}=$ not done; $\mathrm{NA}=$ not available.

most of them are delayed-type hypersensitivity reactions [3-5]. Nevertheless, several authors have described cases of AIHS to pristinamycin [6-10].

The basophil activation test (BAT) is a functional assay mimicking, in vitro, the events that lead to the onset of the clinical symptoms in vivo [11]. BAT is now increasingly widespread and used for the diagnosis of allergy to $\beta$-lactams, NMBA (neuromuscular blocking agents), fluoroquinolones and radio-contrast media (RCM). However, the performance of BAT in the diagnosis of IHS to pristinamycin remains to be documented.

Here, we evaluate for the first time the BAT's specificity and sensitivity for the diagnosis of AIHS to pristinamycin in a cohort of 36 patients who developed IHS reactions after the intake of this antibiotic.

\section{Methods}

All patients were recruited from the Allergology Unit of the Lyon Sud University Hospital, between 2007 and 2013, on the basis of an IHS reaction after the intake of pristinamycin. For all patients, skin tests and BAT were performed simultaneously. The patients were divided into two groups depending on the results of skin tests and oral challenge.

BAT in Pristinamycin Allergy
Group 1 (table 1) included 21 confirmed allergic patients $(\mathrm{M}: \mathrm{F}=4: 17$, mean age $=49.1$ years, range $21-72)$ who presented typical clinical features associated with positive skin tests to pristinamycin. These patients developed severe reactions (the majority of grade II and III according to the Ring and Messmer classification [12]), combining cutaneous, digestive and respiratory signs.

Group 2 (table 2) was composed of 15 patients ( $\mathrm{M}: \mathrm{F}=4: 11$, mean age $=48.6$ years, range $15-77)$ with a positive clinical history and for whom skin tests to pristinamycin and oral challenge, when performed, were negative.

BAT was also performed in 10 control patients $(\mathrm{M}: \mathrm{F}=2: 8$, mean age $=45.9$ years, range $22-67$ ) without a clinical history of IHS to pristinamycin but with suspected allergy to other drugs. Seven of them were diagnosed as nonallergic and 3 as bona fide allergic to iomeprol, ixoglate and pertuzumab, respectively, based on skin tests and clinical history.

BAT was performed using the Allergenicity $\mathrm{Kit}^{\circledR}$ (Beckman Coulter, Villepinte, France), according to manufacturer's recommendations. A 500-mg pristinamycin tablet (Pyostacine ${ }^{\circledR}$, SanofiAventis) was diluted in $10 \mathrm{ml}$ of PBS. The solution was then filtered through a $0.2-\mu \mathrm{m}$ filter. For each patient, 3 concentrations of pristinamycin were tested: $1,0.5$ and $0.1 \mathrm{mg} / \mathrm{ml}$. Venous blood was collected in EDTA-coated tubes. Blood samples were incubated (within $4 \mathrm{~h}$ after sampling) with the 3 different pristinamycin dilutions, an activating solution containing $\mathrm{Ca}^{2+}$, heparin and fluorescent antibodies (CRTh2-FITC, CD3-PC5 and CD203c-PE) for 15 min in the dark. Samples were then fixed, lysed and analyzed on a Navios (Beckman Coulter) flow cytometer. 
Table 2. Demographical, clinical and biological characteristics of the 15 patients with a positive clinical history but a negative challenge to pristinamycin

\begin{tabular}{|c|c|c|c|c|c|c|c|c|c|c|}
\hline Sex & $\begin{array}{l}\text { Age, } \\
\text { years }\end{array}$ & $\begin{array}{l}\text { Time of symp- } \\
\text { tom onset }\end{array}$ & $\begin{array}{l}\text { Severity } \\
\text { grading }\end{array}$ & \multicolumn{3}{|c|}{ Clinical symptoms } & $\begin{array}{l}\text { Prick } \\
\text { test }\end{array}$ & $\begin{array}{l}\text { IDT } \\
(1 / 10)\end{array}$ & Oral challenge & BAT result \\
\hline $\mathrm{F}$ & 54 & $<1 \mathrm{~h}$ & I & - & - & - & - & - & Well tolerated & Negative \\
\hline $\mathrm{F}$ & 42 & $2 \mathrm{~h}$ & I & + & - & - & - & - & Well tolerated & Negative \\
\hline $\mathrm{F}$ & 66 & $<1 \mathrm{~h}$ & I & + & - & - & - & - & Well tolerated & Negative \\
\hline $\mathrm{F}$ & 60 & $<1 \mathrm{~h}$ & I & + & - & - & - & - & Well tolerated & Negative \\
\hline $\mathrm{F}$ & 53 & NA & I & + & - & - & - & - & ND & Anti-IgE nonresponder \\
\hline $\mathrm{F}$ & 63 & NA & $\mathrm{I}$ & + & - & - & - & - & ND & Negative \\
\hline M & 43 & $<1 \mathrm{~h}$ & II & + & - & + & - & - & Well tolerated & Negative \\
\hline $\mathrm{F}$ & 28 & NA & $\mathrm{I}$ & + & - & - & - & - & ND & Negative \\
\hline M & 39 & $>1 \mathrm{~h}$ & I & + & - & - & - & - & Well tolerated & Negative \\
\hline
\end{tabular}

IDT = Intradermal test; $\mathrm{ND}=$ not done; $\mathrm{NA}=$ not available.

Skin tests were performed 1-3 months after the clinical reaction. For each patient, skin prick tests were conducted with a concentration of $50 \mathrm{mg} / \mathrm{ml}$ of pristinamycin. In cases of a negative or doubtful result, an intradermal test was performed using $300 \mu \mathrm{l}$ of one of the three decimal dilutions (from $1 / 10$ to $1 / 1,000$ ) of the prick test's solution. Oral challenges were proposed to 9 patients from group 2; these patients were administered $500 \mathrm{mg}$ of pristinamycin under medical monitoring.

\section{Results}

Our cohort constituted of a majority of women (28/36) suffering from allergic and nonallergic IHS, which is in accordance with data in the literature [13]. Using ROC curve analysis (fig. 1) we determined the optimal positivity threshold for basophil activation (CD203c expression), and results were considered positive when one of the drug dilutions induced more than 7\% CD203c-positive basophils above the negative control value.

Among the 21 confirmed allergic patients (table 1), BAT was positive in 16 cases (fig. 2) and negative in 5 cases. In this population, the mean percentage of CD203cpositive basophils after incubation with pristinamycin was $38 \%$ ( $1 \%$ for the negative control and $73 \%$ for the positive control). All except 2 of these 16 patients responded to the 3 concentrations, and 2 groups of patients could be distinguished (table 1): those who responded

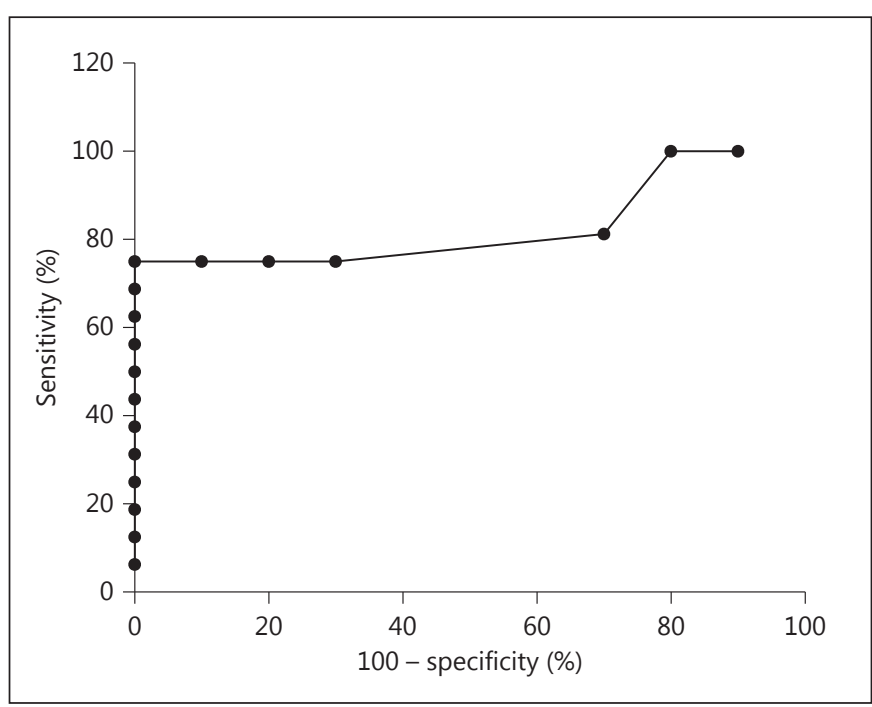

Fig. 1. ROC curve analysis. The optimal threshold determined (using a final concentration of pristinamycin of $1 \mathrm{mg} / \mathrm{ml}$ ), was $7 \%$ of CD203c-positive basophils (sensitivity $=76 \%$ and specificity $=$ $100 \%)$.

strongly to the 3 concentrations and those who responded weakly, but in a dose-dependent manner.

Among the 15 nonallergic patients (table 2), BAT was negative in 11 cases and uninterpretable in 4 cases ( 3 anti-IgE nonresponders and 1 spontaneous basophil activa- 
Fig. 2. Decision tree used for the investigation of the 36 patients suffering from an IHS to pristinamycin.

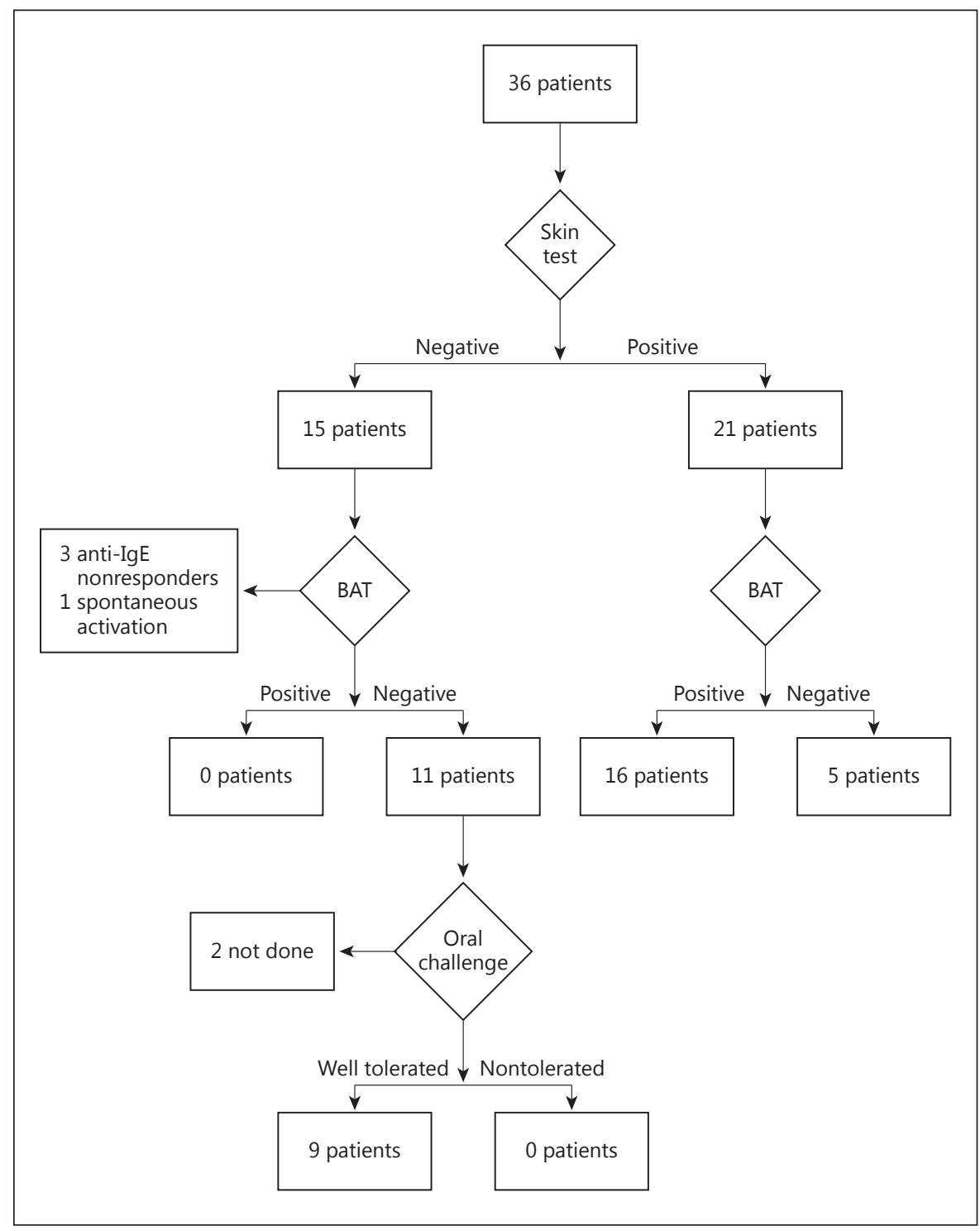

tion). The mean percentage of CD203c-positive basophils in this population was $3 \%$ ( $2 \%$ for the negative control and $73 \%$ for the positive control).

The BAT was negative for the 10 patients of the control population. Based on these results and considering the skin test as the gold standard, the sensitivity of BAT in diagnosing pristinamycin AIHS is $76 \%$ and its specificity is $100 \%$.

\section{Discussion}

Unlike for common food and aeroallergens, the usefulness of biological tests for the diagnosis of AIHS to drugs, for which numerous in vitro assays based on the detection of specific IgE are available, remains to be determined. Drug-specific IgE assays are only available for a few drugs (penicilloyl G, V, ampicilloyl and amoxicilloyl determinants, cefaclor, chlorhexidine, chymopapain, pholcodine, morphine and suxamethonium) [14]. Moreover, drugs are, in general, low-molecular-weight compounds that elicit weak basophil responses when compared to protein allergens. For this reason, the sensitivity of BAT for drugs is poor and depends largely on the offending compound. For instance, the BAT sensitivity in AIHS ranges from 22 to $55 \%$ for $\beta$-lactams, from 36 to $71 \%$ for fluoroquinolones and from 36 to $92 \%$ for NMBAs [15]. In AIHS to RCM, the sensitivity of BAT can reach $100 \%(63-100 \%)$ [15]. However, the studies regarding 
RCM include a limited number of patients and the hyperosmotic nature of RCM may trigger a nonspecific basophil degranulation, affecting the BAT's reliability.

This cohort of pristinamycin-allergic patients reflects a 6-year assessment for the pristinamycin BAT and is the largest ever reported. Although several groups have already described pristinamycin IgE-mediated allergy, mainly case reports have been published [6-10]. The $76 \%$ sensitivity of the BAT in AIHS to pristinamycin is higher than most studies using BAT for other drug allergies. The specificity we report, either in patients who experienced nonallergic IHS to pristinamycin or in control patients, was $100 \%$, confirming the good positive predictive value of BAT in drug hypersensitivity [2].

Both skin tests and oral challenge, which are used in the diagnosis of IHS, are not without risk for patients. We have shown that BAT is highly specific and safe, and that a positive result can help to avoid unnecessary skin contact with allergens. However, considering the 5 AIHS to pristinamycin patients for whom the results were discordant between the skin tests and BAT, negative BAT results cannot exclude the diagnosis of pristinamycin AIHS. Besides, about $5-10 \%$ of patients are not responsive to positive controls in BAT, which makes BAT useless in those cases. Therefore, clinicians should be aware of possible false negative results. Thus, BAT should be consid- ered as a first exploratory test. Although we cannot exclude the existence of false positive results with skin tests, BAT appears insufficient to rule out AIHS. For ethical reasons, we could not perform a challenge test, which is considered as the gold standard, to get a definitive answer of the immunological allergic status of these patients.

Pristinamycin is a mixture of two molecules (pristinamycin IA and IIA) that cannot be tested independently either for BAT or skin testing. However, it remains important to elucidate through which component the sensitization occurs. Since pristinamycin IIA is a macrolide, cross-sensitization with other molecules of the macrolide family may arise. In the evaluation of 3 allergic patients to pristinamycin, Ben Said et al. [7] did not observe any cross-reactivity with spiramycin, roxithromycin, clarithromycin, telithromycin and erythromycin, but this remains to be confirmed.

As a conclusion, due to the good sensitivity and excellent specificity of BAT in the diagnosis of allergy to pristinamycin, multicenter studies should be carried out in order to further determine the clinical value of this test.

\section{Disclosure Statement} terest.

\section{References}

1 Liccardi G, D Amato G, Canonica GW, Salzillo A, Piccolo A, Passalacqua G: Systemic reactions from skin testing: literature review. J Investig Allergol Clin Immunol 2006;16:7578.

2 Ebo DG, Leysen J, Mayorga C, Rozieres A, Knol EF, Terreehorst I: The in vitro diagnosis of drug allergy: status and perspectives. Allergy 2011;66:1275-1286.

3 Barbaud A, Trechot P, Weber-Muller F, Ulrich G, Commun N, Schmutz JL: Drug skin tests in cutaneous adverse drug reactions to pristinamycin: 29 cases with a study of crossreactions between synergistins. Contact Dermatitis 2004;50:22-26.

-4 Blancas-Espinosa R, Conde-Salazar L, PérezHortet C: Occupational airborne contact dermatitis from pristinamycin. Contact Dermatitis 2006;54:63-65.

$\checkmark 5$ Barbaud A, Collet E, Milpied B, Assier H, Staumont D, Avenel-Audran M, et al: A multicentre study to determine the value and safety of drug patch tests for the three main classes of severe cutaneous adverse drug reactions. Br J Dermatol 2013;168:555-562.
6 Boniface S, Magnan A, Vervloet D, ReynaudGaubert M: Allergie à la pyostacine: à propos d'un cas. Rev Fr Allergol Immunol Clin 2004; 44:516-518.

7 Bensaid B, Rozieres A, Berard F, Bienvenu J, Nicolas JF: IgE-mediated allergy to pristinamycin: the value of skin tests and basophil activation tests. Allergy 2009;64:1694.

8 Rubio M, Bousquet PJ, Demoly P: IgE-mediated anaphylaxis to pristinamycin - report of a case. Allergy 2010;65:1198-1199.

-9 Schmutz J-L, Trechot P: Pristinamycin and anaphylactic reaction. Ann Dermatol Vénéréologie 2011;138:720.

10 Pralong P, Nosbaum A, Rouzaire P, Ben Said B, Nicolas J-F, Bérard F: Polysensibilisation rare aux médicaments impliquant plusieurs mécanismes d'hypersensibilité. Rev Fr Allergol 2013;53:601-604.
1 De Weck AL, Sanz ML, Gamboa PM, Aberer W, Bienvenu J, Blanca M, et al: Diagnostic tests based on human basophils: more potentials and perspectives than pitfalls. Int Arch Allergy Immunol 2008;146:177-189.

12 Ring J, Messmer K: Incidence and severity of anaphylactoid reactions to colloid volume substitutes. Lancet 1977;1:466-469.

13 Banerji A, Rudders S, Clark S, Wei W, Long AA, Camargo CA: Retrospective study of drug-induced anaphylaxis treated in the emergency department or hospital: patient characteristics, management, and 1-year follow-up. J Allergy Clin Immunol Pract 2014;2: 46-51.

14 Uyttebroek AP, Sabato V, Bridts CH, Ebo DG: In vitro diagnosis of immediate IgE-mediated drug hypersensitivity: warnings and (unmet) needs. Immunol Allergy Clin North Am 2014; 34:681-689.

15 Song W-J, Chang Y-S: Recent applications of basophil activation tests in the diagnosis of drug hypersensitivity. Asia Pac Allergy 2013. 3:266-280. 